divorcing-by the creation of new managerial bodies, whether in the DHSS or at any other level of the NHS-management from political decisions.

In the last resort, any assessment of the Griffiths proposals must depend on whether the promotion of change or the promotion of consensus, whether maximising the resources available to doctors or maximising the independence of the medical profession, is seen as the more urgent priority in the circumstances facing the NHS today and the immediate future. They certainly do not offer a painless technical or managerial "fix" for the problems of the NHS, for their implications go far beyond applying a managerial top dressing to the organisational structure of the NHS. If that were to be the only outcome of the whole exercise-if the only result were to be the proliferation of cosmetic managerial titles-it is safe to predict the same kind of disillusion that has followed all the other, earlier attempts to make the NHS more management conscious. If, however, all its implications were to be followed up it is clear that there would have to be a sustained campaign to transform the style in which the NHS has been run for the past three and a half decades and that $\mathrm{Mr}$ Fowler-unlike his predecessors-will have to be ready to cope with conflict.

\section{References}

${ }^{1}$ Ministry of Health. National Health Service: the administrative structure of the medical and related services in England and Wales. London: HMSO, 1968.

2 Department of Health and Social Security. National Health Service reorganisation: consultative document. London: DHSS, 1971.

${ }^{3}$ NHS Management Inquiry. Report. London: DHSS, 1983. (Griffiths report.)

4 Royal Commission on the National Health Service. Report. (Cmnd 7615.) London: HMSO, 1979.

${ }^{5}$ Social Services Committee. The government's white papers on public expenditure: the social services. Third report, session 1979-80. London: HMSO, 1980.

${ }^{6}$ Department of Health and Social Security. Reply by the government to the third report from the social services committee, session 1979-80 (Cmnd 8086.) London: HMSO, 1980.

7 Department of Health and Social Security. Management arrangements for the reorganised National Health Service. London: HMSO, 1972.

8 Department of the Environment. Streamlining the water industry. Press notice, 29 September 1983.

9 Klein R, Lewis J. The politics of consumer representation. London: Centre for Studies in Social Policy, 1976.

${ }^{10}$ Monopolies and Mergers Commission. Severn-Trent water authority. London: HMSO, 1981.

11 Department of Health and Social Security. Performance indicators: national summary for 1981. London: DHSS, 1983.

\title{
The consultant's role in NHS management*
}

\section{JOHN CHAWNER}

The Griffiths report ${ }^{1}$ must be considered in conjunction with the activities of the steering committee on management budgets, ${ }^{2}$ the joint group on performance indicators, the Körner committee, ${ }^{3}$ and the 1982 reorganisation of the National Health Service.

The NHS management inquiry proposes radical changes that could affect the whole nature of health care delivery in this country. The changes are to take place without legislation, and though the Secretary of State has avowed that consultations will take place, the deadline for these, 9 January 1984, gives little time and implementation is planned for April 1984. The BMA has been asked for its views, but I hope that members of parliament will also have an opportunity to debate the issues thoroughly.

I think that it is satisfactory that the Chief Medical Officer is on the supervisory board proposed by Griffiths, as he has not always enjoyed a high place in the Department of Health and Social Security's hierarchy. Accountability is clearly defined lower down the scale, but it is not clear how this will work in the supervisory board. The board will be an immensely powerful body as it will have to take to itself an undisclosed amount of the role of the Secretary of State and the DHSS. With friendly government appointees there may not be cause for alarm, but what would have happened in 1974 at the time of Barbara

* This paper is based on a talk given at a course on consultant leadership in the NHS organised by the BMA in Darlington on 24 November 1983.

\section{Bangor, Gwynedd, North Wales LL57 $2 \mathrm{HQ}$}

JOHN R A CHAWNER, MB, FRCOG, consultant obstetrician and gynaecologist, chairman of the private practice committee of the BMA, and member of the Central Committee for Hospital Medical Services

Correspondence to: Yr Hafod, Holyhead Road, Bangor, Gwynedd LL57 2HQ.
Castle's confrontation with the consultants if such a board had existed ${ }^{4}$ Griffiths extols the important role of the clinician in the NHS, yet there is no formal proposal to ensure that a clinician is on the supervisory board or the management board.

The management board is also oriented to professional management and will not contain anyone who has any experience of delivery of health care at the only level where it matters-the patient.

At regional level a general manager will be appointed regardless of discipline by the chairman of the health authority. I note that he is to make explicit the main decisions reserved to the authority itself. Does this mean that an official will now decide what the authority can and cannot discuss? The abolition of functional management structures is proposed. Apart from an apparent strengthening of the power of the often politically appointed chairman I am not too worried about changes at this level from the clinicians' point of view.

The district chairman is to be given the task of appointing the district manager, who may be from any discipline but in practice is likely to be one of the existing chief officers. No doubt the chairman will have consultations before making such appointments, but the special role of the clinician envisaged in the report surely makes the consultants' views of paramount importance. If clinicians are to have greater management functions it should be mandatory for chairmen to consult them.

The proposals at unit level cause me most concern. Griffiths says that day to day decisions should be taken in the main hospital and other units and should not be taken elsewhere. All clinicians already make daily management decisions at the point of health care delivery. Shall I admit a Wertheims hysterectomy next week-will there be sufficient anaesthetists, juniors, and nurses available on that day ? What is the likely effect on other patients on the waiting list ? Shall we continue to prescribe a particularly expensive drug? What should I say to my senior registrar, who is being criticised by senior nursing management ? Should I make yet another effort to have my secretary promoted? The decisions are endless, and I believe that we are good at them. 


\section{Financial control and measurement of output}

I have the greatest doubts about the closer participation of clinicians in the management process particularly as regards financial control and measurement of output.

Financial control is central to the Griffiths philosophy and is the subject of a specific inquiry-the steering committee on management budgets. This committee is concerned that clinicians should be budget holders. Having seen the effects on other budget holders, such as those in $x$ ray and pathology departments, I am not enthusiastic. It is senseless for a clinician to hold a budget unless the following factors are fulfilled.

(1) He has the necessary training to enable him to evaluate the relevant management information.

(2) He has full control of his unit-for example, in obstetrics, control of the medical salary allocation, which should cover the statutory allowance for salary, study leave, and locums. He should have similar control over midwives at all levels, implied control of pupil midwives, cleaners, laboratory technicians, secretaries, record staff, closure of wards, control of relevant community budgets to include district midwives, and part of the work of health visitors; equipment allocation and reviews of replacement of old equipment; and review of travelling expenditure.

(3) $\mathrm{He}$ is prepared to decide allocation of budgets between himself and his colleagues. Review of spending in other departments, such as pharmacy, $x$ ray, and pathology, would need to be kept under constant review.

(4) He will have to be liberally rewarded in financial terms for the extra work. He will be taking on the full management role of one of Mr Griffiths's managers plus his own clinical duties. In all these functions I am talking about clinical budget holders, not the unit managers. Failure by the government to make any payment for the considerable extra work of unit management representatives does not instil any confidence that it would be more forthcoming with budget holders.

(5) $\mathrm{He}$ is absolved from the effects of financial cuts by ministers. The clinicians are the decision makers known to the general public. No one knows, or cares, who the chairman or administrator or senior nursing officer is, but, even now, if services are deficient-that is, waiting lists-the consultant is often the first to be blamed. How much more will he be blamed if he is known to be responsible for his budget.

How will such a paragon be identified? No doubt there are some who would be eager and willing to accept such responsibilities but who might not have the enthusiastic support of their colleagues. There might be some talented individuals who would be suitable budget holders but have clinical interests elsewhere that would preclude them because of the considerable time needed to fulfil their budgetary responsibilities. We would be doing a grave disservice to many of those we represent if we were to accept Griffiths uncritically. Few consultants have skills in modern management methods, and it would be wrong to expect existing consultants to acquire them. We were appointed on the basis of our clinical skill, and until the royal colleges agree-and the necessary training exists-clinicians should not be expected to branch out into management. Had I wished to take on the role envisaged in the report I would have enrolled in the packing departments of Sainsbury's and not in a medical school. Nurses have gained a reputation as poor managers, and I believe this is mainly due to them having huge budgets to control with no training in how to do so. There is no evidence that clinicians would be any more able, and they might well suffer the same fate.

These remarks apply also to the difficulties that would occur if the unit manager were to be a clinician. For those willing to accept such a position it would mean a substantial change in their style of work and, in most cases, loss of income and prospects. It has been suggested that these losses would be of the order of $£, 10000$ a year, a figure I would not dispute-indeed, it might be too low in many cases.

Management budgets along the lines discussed are expected to be introduced and have already been brought in on a demonstration model basis in four districts-North Tees, Southmead, Ealing, and Basingstoke. It is unclear how long these "demonstrations" are to last, how their results will be assessed and in what depth, and whether the profession will be consulted before wholesale introduction. This happened with the Salmon recommendations for senior nursing staff structure, which I believe started as a "pilot" scheme at Guy's Hospital and were then disastrously introduced without assessment. ${ }^{5}$ I would not think that these Griffiths models could be assessed properly until they had been going for a couple of years. It is one thing for such exercises to be set up by top level management consultants, as is happening in these districts, and another for our own administrators to attempt to do so.

\section{Effective management demands effective information}

Effective management demands effective information services, and it is here that Körner comes in. We have, over the years, expressed grave doubts about the accuracy and hence usefulness of the Hospital Inpatient Activity Analysis system, and I believe that this is now generally accepted. The Körner reports represent a genuine attempt to replace the present system with something better. However brilliantly designed the system is it will only ever be as good as the information that is fed into it. In my view the input will continue to be poor because of lack of motivation or reward for suppliers of such information. A possible solution would be to recognise the paramount role of the consultant's secretary in the management process at user level and to do so further by enhancing her salary and status.

A further worrying feature of the Körner reports is that despite a recommendation by the Joint Consultants Committee there is no obvious intention to test the system objectively before its general introduction.

Coupled with information are performance indicators and the not unreasonable idea of whether the consumer is getting value for money. The joint group on performance indicators has been looking at this problem. I can see no objection to questions being asked as to why, say, a hysterectomy costs twice as much in one district as in another comparable one, and a consultant who keeps his patients in hospital much longer than average should be asked to justify his decision. Questions of comparability of quality are much more complex, however, and the committee has just started to apply itself to this. As one member of the Central Committee for Hospital Medical Services explained, he treats patients with intractable pain and is reluctant to discharge them afterwards because the social workers in his area are on strike and there is often no one to look after the patients when they go home. A harder hearted consultant might discharge them immediately after treatment to a life of misery at home. Who would be judged the best by performance indicators?

I hope that such economic considerations are not going to perpetuate the absurdities of which we are all aware-for example, the rule that patients may receive only a limited amount of drugs on discharge from hospital to protect the pharmacy budgets, although it clearly costs the taxpayer much more to prescribe subsequently through dispensing chemists.

The Griffiths document is deceptively simple but proposes profound changes that may make the consultants' way of life entirely different. A lot will depend on unit and clinical budgeting and how it evolves. Limited clinical budgeting gives the clinician all responsibility and no power. Full control of the budget may be outside either his skill or the time he has available. I favour consultants being cost conscious, and this is one of the spin off benefits of private practice. I do not know the real cost of the obstetric service for which I am responsible, and I hope that the effect of the Griffiths inquiry and other activities would be to provide this information. The manager should be able to provide this information and to discliss the organisation 


\section{Prescribing contraceptives to minors}

The secretary of the BMA, Dr John Havard, has written to the Secretary of State for Social Services, Mr Norman Fowler, urging the Department's continued support for the advice given by the BMA and the General Medical Council to doctors faced with the problems of prescribing contraceptives to minors without the parents' consent. This follows a meeting of the central ethical committee on 30 November at which the present advice of the BMA to doctors on this subject was endorsed.

The letter expressed the concern of the association at the pressure being exercised by certain groups to introduce legal prohibition of the provision of contraception to minors. In the letter Dr Havard said: "I must say immediately that we regard sexual activity at a young age as being undesirable on medical grounds, including the risk of infection by sexually transmitted diseases and an increased risk of carcinoma of the cervix. Additionally, we believe that early sexual activity at any age requires emotional as well as physical maturity if it is to contribute to a person's relationship, rather than acting as a destructive influence.

"It was with these thoughts in mind that the BMA wrote the advice currently set out in the Handbook of Medical Ethics. ${ }^{1}$ We know that a proportion of girls under the age of 16 are sexually active, and we are satisfied that the guidance in the ethical handbook is wise and sensible advice to doctors. We believe that the guidance currently issued by the DHSS and the GMC reflects a moderate consensus allowing doctors to provide advice to girls from stable family backgrounds, where the profession is almost invariably successful in persuading girls to involve their parents, and also to deal with cases where parental relationships with the child have broken down irretrievably and where the doctor may be the girl's only contact with a responsible adult."

'British Medical Association. Handbook of medical ethics. London:BMA, 1981:18.

\section{Improved milage allowances}

The negotiating subcommittee of the CCHMS is considering an offer from the DHSS on improvements to the milage allowance scheme. The offer takes account of the Inland Revenue's decision to tax, from 1 December, the home to headquarters element of hospital doctors' milage. The offer is broadly similar to the one that has been accepted by community doctors through the Whitley machinery and entails the reimbursement of a large proportion of standing charges for regular users over 9000 miles, an increase in all lump sum compensation and milages, a broadening of the criteria for regular user status, and compensation for additional depreciation for high milage users, all in return for the cessation of payment for journeys from home to principal hospital other than in emergencies. The negotiators are seeking further information on the implication of these proposals and will be discussing them in detail in a joint working party with representatives of junior staff, who are also affected.

\section{Time expired senior registrars}

\section{"Grossly inadequate" provision for front line medical care in inner cities, say GPs}

Leaders of Britain's 29000 general practitioners are to protest to $\mathrm{Mr}$ Norman Fowler that the $£ 9 \mathrm{~m}$ provision by the Department of Health and Social Security to improve health care in inner cities is "grossly inadequate." The General Medical Services Committee estimates that more than twice as much is necessary to produce a significant improvement in primary health care services in deprived inner city areas over the next four years.

Commenting, Dr John Ball, chairman of the GMSC, said: "Bearing in mind that by no means all of this goes to general practice, this sum of $f 9 \mathrm{~m}$ is grossly inadequate. It has taken the government over two years to produce even this limited response to the Acheson report, Primary Health Care in Inner London, which made a number of recommendations to improve health care in inner cities, but no response has yet been announced to the majority of the recommendations of this report. Moreover, the manner in which the announcement of enhanced improvement grants was made has caused considerable confusion and concern among GPs. The fact that the scheme was announced without there being available supporting guidance on how it was to be administered has created considerable difficulties for family practitioner committees in advising doctors on its implementation. Without including the date at which the scheme would become operative, the announcement made clear that existing projects would not be eligible. The amount, combined with the decision to set a target allocation for the current financial year, has created added anxiety. We consider any such target to be unrealistic and regret the imposition of such restrictive conditions. If GPs are to have any chance of meeting such a short deadline, it is vital that the Department of Health alerts all relevant local authorities of the need to treat all such requests for planning in respect of practice premises as very urgent."
Under an agreement made by the Joint Consultants Committee provision was made to allow time expired senior registrars to continue in their appointment provided that they applied for all consultants posts as they became available. It has been reported to the general purposes subcommittee of the CCHMS that some senior registrars are applying for posts and then withdrawing. The central manpower committee discovered that this was occurring in the shortage specialties and in the oversubscribed ones, making manpower statistics unreliable. The chairman of the JCC has said that where this occurred the postgraduate dean in the region from which the applicants had come should be told so that pressure could be put on the senior registrars to be honest in their applications and to ensure a more equitable distribution of senior hospital staff. The general purposes subcommittee supported this and has told the Central Committee for Community Medicine and Community Health so that community physicians may notify postgraduate deans where applicants withdrew before the interview stage.

The consultant's role in NHS management-continued from page 1817

with the clinicians. Levels of funding of the Health Service are political decisions: doctors should not be expected to take responsibility for fitting their own quart into the Secretary of State's pint pot.

A primary function of the BMA is to protect the interest of its members. I am not certain that it will do so by agreeing to the Griffiths report at this stage. Those who represent the profession should clarify the many points that have been raised: until then they should reserve judgment.

\section{References}

${ }^{1}$ NHS Management Inquiry. Report. London: DHSS, 1983. (Griffiths report.)

${ }^{2}$ Anonymous. From the JCC. $\mathrm{Br} \mathrm{Med} \mathcal{F} 1983 ; 287: 1396$.

${ }^{3}$ National Health Service and Department of Health and Social Security Steering Group on Health Services Information. First report. London: NHS/DHSS, 1982.

4 Anonymous. Damaging and needless collision. Br Med $\mathcal{F}$ 1974;ii :305-6. 5 Committee on Senior Nursing Staff. Report. London: HMSO, 1966. (Salmon report.) 